\title{
The Dark Side of hormone prescription
}

\author{
Richard J Auchus 1,2,3 $^{1,2}$ \\ ${ }^{1}$ Division of Metabolism, Endocrinology, and Diabetes, Department of Internal Medicine, University of Michigan, Ann Arbor, Michigan, USA \\ 2Department of Pharmacology, University of Michigan, Ann Arbor, Michigan, USA \\ ${ }^{3}$ Veterans Affairs Medical Center, Ann Arbor, Michigan, USA
}

Correspondence should be addressed to R J Auchus: rauchus@med.umich.edu

'Beware of the Dark Side... Once you start down the dark path, forever will it dominate your destiny, consume you it will.'

- Yoda, Star Wars V - The Empire Strikes Back

Kendel, Reichstein, and Hench shared the Nobel Prize in 1950 for the isolation and therapeutic use of cortisone. Hench, a rheumatologist used the anti-inflammatory properties of cortisone to treat rheumatoid arthritis, with dramatic results. Soon afterward, Thorn and Forsham treated adrenal insufficiency with cortisone (1), a lifesaving intervention that changed a uniformly fatal illness into a chronic disease. Amazing, Lazarean results were also obtained when insulin was used to treat type 1 diabetes a century ago. Impressive clinical responses are routinely obtained with thyroxinetherapy for severehypothyroidism, estrogen for ovarian failure, growth hormone for pituitary dwarfism, and most recently, recombinant parathyroid hormone for hypoparathyroidism (2). These sweeping responses to properly administered hormone replacement in the setting of severe deficiency states are what prompted many of us to pursue the noble field of clinical endocrinology.

Capitalizing on the precedents of hormone replacement therapy for severe deficiency states, the science-based, intellectually honest, and evidence-based practice of endocrinology has been grossly corrupted through the actions of charlatans, who have invented pseudo-diseases and promulgated hormone misuse for personal profit. For the purposes of this article, I will define hormone abuse as the prescription and administration of hormones neither for treatment of a deficiency state nor a pharmacologic use for an accepted indication. Often, the goal is to elicit short-term physiologic and psychologic effects of supraphysiologic hormone exposures. Irwig and colleagues developed a position statement for the American Association of Clinical Endocrinologists (AACE) (3) to address the widespread misuse of hormone therapies, uses that are not consistent with the recommendations of professional societies, and the guidance of the United States Food and Drug Administration.

The AACE position statement systematically reviews the patterns of misuse for testosterone, growth hormone (rhGH), thyroxine and thyroid hormones, and cortisol. The authors contrast the true endocrine deficiency states with the putative conditions that prompt the peddling of off-label hormone prescriptions and homeopathic supplements. They review the recognized adverse events related to hormone doping, including infertility and cardiovascular events with androgens $(4,5)$; edema and glucose intolerance for $\mathrm{rhGH}(6)$; atrial or ventricular fibrillation for thyroid hormones (7); the litany of adverse effects from glucocorticoids, ranging from weight gain and glucose intolerance to bone loss and avascular necrosis (8). The position statement provides a good compilation of references for adverse events and of the terminology used for duping patients to follow spurious diagnostic algorithms to justify the doping practices. The work of Irwig et al. will serve as a useful reference for the practicing endocrinologist to address clients who might be vulnerable to the lure of the charlatans on the Dark Side.

The perception that hormone abuse is 'not like narcotic abuse' or 'some petty victimless crime' is a perilous delusion. Significant adverse effects, perceived or physiologic dependency, and the economic burden of those drugs appropriately not covered through insurance programs extract a substantial toll from these victims and the healthcare system over time. As the enhanced sense of well-being that largely derives from the placebo effect (9) rapidly wane, the usual response is dose escalation or adding yet another form of snake oil. Doping is doping, abuse is abuse, and failing to adhere to the oath 'primum non nocere' is unacceptable behavior under any circumstances. More to the point, ethical medical practice informs patients of the risks and benefits of any proposed therapeutic intervention and balances these factors before

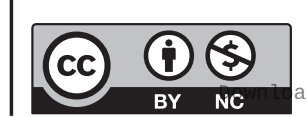

This work is licensed under a Creative Commons Attribution-NonCommercial 4.0 International License. ded from Bioscientifica.com at 04/26/2023 10:51:52AM 
treating. Even when the client claims to accept the risks and expresses a desire to dope with hormones, equivalent to the heroin addict begging their supplier for another high, the only ethical answer is to decline.

Many of these patients who are duped into hormone doping suffer from fatigue, unrealistic expectations, and false perceptions of reality, thanks to the demands and vices of modern society. Poor sleep, reliance on heavily processed foods, insufficient physical activity, distorted expectations, and excessive personal demands without emotional support take its toll on all of us, and people want a simple diagnosis with an equally simple solution that consists of a pill or a shot. The lure of hormone treatment elicits a quixotic appeal as a simple solution to a natural organic condition, and the miraculous responses observed for treatment of the true deficiency states are blissfully enticing. Unfortunately, the truth is that there is no quick fix for these common multi-factorial symptoms, which countless individuals experience. Clients do not like to hear that their complaints are due to a non-medical problem, or at least not a single discreet disease, and the remedy is a series of environmental and personal steps that take time, effort, and guidance to achieve. More poignantly, the pursuit of hormone doping detracts attention from the real problems that are causing the patients' complaints and ultimately creates more problems than solutions. Endocrinologists are often called upon to clean up the mess after the transient feelings of improvement from hormone doping wane and the adverse consequences manifest. I can assure you that 'hormone detoxification' is not an enjoyable experience, neither for the patient nor the doctor, a quandary that only strengthens the parallels of hormone doping with narcotic abuse.

Is the position statement of Irwig et al. merely preaching to the choir or will this compilation make a difference to stem the tide of illicit hormone prescription? Dissemination of this treatise to primary care practitioners is likely to raise awareness and better prepare front-line healthcare workers to discourage patients from pursuing the seductive yet dangerous journey to the Dark Side. The document might be useful ammunition for legal actions against the charlatans, either for malpractice claims or disciplinary actions from state medical boards. While several papers describing the perils of androgen abuse have appeared (10), this first comprehensive hormone abuse statement might form a template for other professional societies, to strengthen the voices against hormone doping.

Moreimportant thanknowing whatnot todois knowing what the primary care providers and endocrinologists should do. We all want people to feel better and to live more pleasant and productive lives, but the solution is to define and correct the roots of the problem. While we might not be able to satisfy everyone, physicians must, first and foremost, validate and accept the patients' concerns and perceptions of unwellness, lest we lose our credibility. We can show empathy, rule out common treatable diseases, and provide a rational explanation for the multi-faceted problem and a few simple non-medical steps to start the road to improvement. Almost every adult in the United States would benefit from a visit to a physical therapist and a sleep study. While my suggestions certainly stretch outside the scope of conventional subspecialty practice, a blunt dismissal does not accomplish anything and only encourages the client to become a hormone doping addict. The opiate crisis has distracted attention from the more socially acceptable but equally tragic epidemic of hormone abuse. The AACE position statement is a valuable step in the long road to curbing illicit hormone prescription.

'In the end, cowards are those who follow the Dark Side. When you look at the Dark Side, careful you must be. For the Dark Side looks back.'

\section{- Yoda, Star Wars III - Revenge of the Sith}

\section{Declaration of interest}

RJ A is a paid consultant for the US Anti-Doping Agency.

\section{Funding}

This work did not receive any specific grant from any funding agency in the public, commercial or not-for-profit sector.

\section{References}

1 Miller WL. A brief history of adrenal research: steroidogenesis: the soul of the adrenal. Molecular and Cellular Endocrinology 2013 371 5-14. (https://doi.org/10.1016/j.mce.2012.10.023)

2 Mannstadt M, Clarke BL, Vokes T, Brandi ML, Ranganath L, Fraser WD, Lakatos P, Bajnok L, Garceau R, Mosekilde L, et al. Efficacy and safety of recombinant human parathyroid hormone (1-84) in hypoparathyroidism (REPLACE): a double-blind, placebocontrolled, randomised, phase 3 study. Lancet: Diabetes and Endocrinology 20131 275-283. (https://doi.org/10.1016/S22138587(13)70106-2)

3 Irwig MS, Fleseriu M, Jonklaas J, Tritos NA, Yuen KCJ, Correa R, Elhomsy G, Garla V, Jasim S, Soe K, et al. Off-label use and misuse of testosterone, growth hormone, thyroid hormone, and adrenal supplements: risks and costs of a growing problem. Endocrine Practice 202026 340-353. (https://doi.org/10.4158/PS-2019-0540)

4 Baggish AL, Weiner RB, Kanayama G, Hudson JI, Lu MT, Hoffmann U \& Pope Jr HG. Cardiovascular toxicity of illicit anabolic-androgenic
This work is licensed under a Creative Commons Attribution-NonCommercial 4.0 International License. ded from Bioscientifica.com at 04/26/2023 10:51:52AM via free access 
steroid use. Circulation 2017135 1991-2002. (https://doi.org/10.1161/ CIRCULATIONAHA.116.026945)

5 Kanayama G, Hudson JI, DeLuca J, Isaacs S, Baggish A, Weiner R, Bhasin S \& Pope Jr HG. Prolonged hypogonadism in males following withdrawal from anabolic-androgenic steroids: an under-recognized problem. Addiction 2015110 823-831. (https://doi.org/10.1111/ add.12850)

6 Blackman MR, Sorkin JD, Munzer T, Bellantoni MF, BusbyWhitehead J, Stevens TE, Jayme J, O'Connor KG, Christmas C, Tobin JD, et al. Growth hormone and sex steroid administration in healthy aged women and men: a randomized controlled trial. JAMA 2002288 2282-2292. (https://doi.org/10.1001/jama.288.18.2282)

7 Bhasin S, Wallace W, Lawrence JB \& Lesch M. Sudden death associated with thyroid hormone abuse. American Journal of Medicine 198171 887-890. (https://doi.org/10.1016/0002-9343(81)90392-2)
8 Bornstein SR, Allolio B, Arlt W, Barthel A, Don-Wauchope A, Hammer GD, Husebye ES, Merke DP, Murad MH, Stratakis CA, et al. Diagnosis and treatment of primary adrenal insufficiency: an Endocrine Society clinical practice guideline. Journal of Clinical Endocrinology and Metabolism 2016101 364-389. (https://doi. org/10.1210/jc.2015-1710)

9 Snyder PJ, Bhasin S, Cunningham GR, Matsumoto AM, StephensShields AJ, Cauley JA, Gill TM, Barrett-Connor E, Swerdloff RS, Wang C, et al. Effects of testosterone treatment in older men. New England Journal of Medicine 2016374 611-624. (https://doi. org/10.1056/NEJMoa1506119)

10 Pope Jr HG, Wood RI, Rogol A, Nyberg F, Bowers L \& Bhasin S. Adverse health consequences of performance-enhancing drugs: an endocrine society scientific statement. Endocrine Reviews 201435 341-375. (https://doi.org/10.1210/er.2013-1058)

Received in final form 29 July 2021

Accepted 2 August 2021

Accepted Manuscript published online 4 August 2021
This work is licensed under a Creative Commons Attribution-NonCommercial 4.0 International License. ded from Bioscientifica.com at 04/26/2023 10:51:52AM via free access 